Красинский Владислав Вячеславович кандидат юридических наук, эксперт Российского общественного института избирательного права (РОИИП)

Источник публикации: Красинский B.B. О правовой природе актов избирательных комиссий в Российской Федерации // Современное право. 2009. № 11; www.krasinskiy.ru

\title{
О ПРАВОВОЙ ПРИРОДЕ АКТОВ ИЗБИРАТЕЛЬНЫХ КОМИССИЙ В РОССИЙСКОЙ ФЕДЕРАЦИИ
}

Вопрос о правовой природе юридических актов избирательных комиссий имеет тройственный характер.

С одной стороны, данный вопрос тесно связан с проблемой источников права, поскольку правовая природа государственных актов влияет на их способность выступать социальными регуляторами общественных отношений. Качество источника права и роль регулятора общественных отношений в полной мере относится лишь к нормативным правовым актам, содержащим правовые нормы.

С другой стороны, природа правовых актов определяет отношение субъектов права к реализации предписаний, закрепленных в этих государственных документах. Индивидуальные правовые акты распространяют свое действие на конкретных субъектов права, в то время как правовые акты нормативного характера действуют в отношении неопределенного круга субъектов. Нормативные правовые акты и их строгая иерархия по отношению друг к другу выступают предпосылками законности. Специалисты в области нормотворчества справедливо отмечают, что «главной целью нормативных актов является установление правовых режимов, направленных на осуществление правового порядка и утверждение режима законности на том правовом пространстве, на которое распространяется действие этих актов» ${ }^{1}$. Вести речь о законности, подразумевая строгое и неуклонное исполнение индивидуальных правовых актов всеми субъектами права, бессмысленно.

Наконец, с помощью правовых актов избирательные комиссии реализуют свою компетенцию. 
В соответствии с пунктом 13 статьи 21 Федерального закона «Об основных гарантиях избирательных прав и права на участие в референдуме граждан Российской Федерации», подпунктом 3 статьи 19 Федерального закона «О выборах Президента Российской Федерации», пунктом 3 статьи 25 Федерального закона «О выборах депутатов Государственной Думы Федерального Собрания Российской Федерации» ЦИК России наделена полномочиями принимать инструкции и иные нормативные акты по вопросам применения федеральных законов о выборах. Акты, принимаемые Центральной избирательной комиссией Российской Федерации, имеют различную правовую природу. Большая часть актов ЦИК России носит правоприменительный характер, поскольку избирательные комиссии являются, в первую очередь, правоприменительными органами. Правоприменительная деятельность избирательных комиссий подчинена задаче наиболее полной реализации избирательных прав граждан. Среди правоприменительных актов ЦИК России следует выделить акты нормативного толкования (т.н. интерпретаџионные акты). Данные акты не создают новых норм права. Их значение заключается в уточнении и разъяснении действующего права в целях его правильной и эффективной реализации. Примерами актов нормативного толкования служат: Постановление Центральной избирательной комиссии Российской Федерации от 21 сентября 1999 г. № 15/114-3 «О Разъяснениях порядка реализации избирательных прав военнослужащих и сотрудников правоохранительных органов в период подготовки и проведения выборов депутатов Государственной Думы Федерального Собрания Российской Федерации третьего созыва», Постановление Центральной избирательной комиссии Российской Федерации от 23 марта 2007 г. № 203/1272-4 «О Разъяснении порядка применения пункта 1.1., подпунктов «в.1», «в.2» пункта 24, подпунктов «б.1», «б.2» пункта 25, подпунктов «з», «и» пункта 26 статьи 38 Федерального закона «Об основных гарантиях избирательных прав и права на участие в референдуме граждан Российской Федерации», Постановление Центральной избирательной комиссии Российской Федерации от 1 ноября 2007 г. № 51/432-5 «О разъяснениях порядка деятельности иностранных 
(международных) наблюдателей и об удостоверении иностранного (международного) наблюдателя при проведении выборов депутатов Государственной Думы Федерального Собрания Российской Федерации пятого созыва» и ряд других актов-разъяснений. Разъяснения, не создавая новых норм права, вместе с тем, обеспечивают единообразное применение федеральных законов ${ }^{2}$.

Особый блок актов толкования образуют акты методического характера: К ним относятся: Постановление Центральной избирательной комиссии Российской Федерации от 07 апреля 2005 г. № 142/975-4 «Об утверждении Методических рекомендаций по организации деятельности избирательных комиссий субъектов Российской Федерации и созданных при них контрольно-ревизионных служб по проведению проверок использования бюджетных средств, выделенных избирательным комиссиям, комиссиям референдума для подготовки и проведения федеральных выборов и референдумов», Постановление Центральной избирательной комиссии Российской Федерации от 27 марта 2006 г. № 174/1121-4 «Об утверждении Методических рекомендаций по организации деятельности избирательных комиссий и созданных при них контрольно-ревизионных служб по контролю за избирательными фондами кандидатов, избирательных объединений, достоверностью представленных сведений о доходах и об имуществе», Постановление Центральной избирательной комиссии Российской Федерации от 24 мая 2006 г. № 176/1131-4 (в ред. от 12 октября 2007 г.) «О Методических рекомендациях о порядке формирования территориальных избирательных комиссий, избирательных комиссий муниципальных образований, окружных и участковых избирательных комиссий» и др. Методические рекомендации утверждаются постановлениями или протоколами заседаний Центральной избирательной комиссии Российской Федерации ${ }^{3}$. Несмотря на рекомендательный характер данных документов, предполагающий вариант поведения субъектов права, Методические рекомендации официально разъясняют избирательное законодательство и обеспечивают его единообразное применение. 
Незначительную часть актов Центральной избирательной комиссии Российской Федерации можно назвать нормативными правовыми актами. Нормативность характеризует свойство данных документов выступать регулятором общественных отношений. В Постановлении Государственной Думы Федерального Собрания Российской Федерации от 11 ноября 1996 г. № 781-II ГД «Об обращении в Конституционный Суд Российской Федерации» приводятся определения нормативного правового акта и правовых норм. «Нормативный правовой акт - это письменный официальный документ, принятый (изданный) в определенной форме правотворческим органом в пределах его компетенции и направленный на установление, изменение или отмену правовых норм. Под правовыми нормами принято понимать общеобязательные государственные предписания постоянного или временного характера, рассчитанные на многократное применение» ${ }^{4}$.

Компетенция Центральной избирательной комиссии Российской Федерации по изданию нормативных правовых актов носит ограниченный характер и, как правило, прямо предусмотрена в соответствующих федеральных законах о выборах. В соответствии с подпунктом 1 пункта 2 статьи 6 Федерального закона «О Государственной автоматизированной системе Российской Федерации «Выборы» ЦИК России устанавливает порядок использования ГАС «Выборы» при подготовке и проведении выборов в референдума в части, не урегулированной федеральными законами. Принятие некоторых нормативных правовых актов ЦИК России предусмотрено пунктом 11 статьи 16, пунктом 7 статьи 57, пунктами 14 и 15 статьи 64 Федерального закона «Об основных гарантиях избирательных прав и права на участие в референдуме граждан Российской Федерации». Федеральным законом «О выборах депутатов Государственной Думы Федерального Собрания Российской Федерации» предусмотрено издание ЦИК России более тридцати нормативных правовых актов, устанавливающих порядок учета и отчетности по средствам избирательных фондов, порядок использования технических средств подсчета голосов, порядок электронного голосования и др 5 
Нормативные правовые акты ЦИК России содержат общеобязательные правила (нормы права), рассчитаны на множество типичных ситуаций и регулируют общественные отношения, связанные с выборами органов государственной власти и органов местного самоуправления. В их число, например, входят: Постановление Центральной избирательной комиссии Российской Федерации от 23 июля 2003 г. № 19/137-4 «О Положении об обеспечении безопасности информации в Государственной автоматизированной системе Российской Федерации «Выборы», Постановление Центральной избирательной комиссии Российской Федерации от 7 августа 2003 г. г. (в ред. от 27 сентября 2006 г.) № 20/144-4 «О временном порядке голосования по почте при проведении выборов в органы государственной власти субъекта Российской Федерации, органы местного самоуправления», Постановление Центральной избирательной комиссии Российской Федерации от 3 ноября 2003 г. № 49/463-4 «Об утверждении Инструкции по организации доступа к персональным данным и иной конфиденциальной информации, обрабатываемой на комплексах средств автоматизации ГАС «Выборы», Постановление Центральной избирательной комиссии Российской Федерации от 28 февраля 2007 г. (в ред от 19 ноября 2008 г.) «Об Инструкции по размещению данных Государственной автоматизированной системы Российской Федерации «Выборы» в сети Интернет», Постановление Центральной избирательной комиссии Российской Федерации от 18 апреля 2007 г. (в ред от 6 июля 2007 г.) № 4/24-5 «Об Инструкции о порядке и формах учета и отчетности политической партии, ее регионального отделения о поступлении средств в избирательные фонды и расходовании этих средств при проведении выборов депутатов Государственной Думы Федерального Собрания Российской Федерации», Постановление Центральной избирательной комиссии Российской Федерации от 3 мая 2007 г. № 6/53-5 «Об Инструкции о порядке и формах учета и отчетности кандидатов о поступлении средств в избирательные фонды и расходовании этих средств при проведении выборов Президента Российской Федерации», Постановление Центральной избирательной комиссии Российской Федерации от 28 июня 2007 г. (в ред. от 22 января 2008 г.) № 18/153-5 «Об 
Инструкции по организации единого порядка установления итогов голосования, составления протоколов избирательных комиссий, определения результатов выборов, получения, передачи и обработки информации с использованием Государственной автоматизированной системы Российской Федерации «Выборы» при проведении выборов Президента Российской Федерации».

Как правило, нормативные правовые акты ЦИК России являются временными, т.е. распространяют свое действие на период конкретных федеральных избирательных кампаний.

Разновидностью нормативных правовых актов ЦИК России являются соглашения, касающиеся взаимодействия избирательных комиссий с другими государственными органами в процессе организации и проведения выборов. Примерами подобных нормативных правовых документов следует считать Соглашение о взаимодействии Центральной избирательной комиссии Российской Федерации и Министерства внутренних дел Российской Федерации от 21 февраля 2005 г., Соглашение между Центральной избирательной комиссией Российской Федерации и Федеральной налоговой службой о взаимодействии и взаимном обмене информацией от 2 июля 2007 г. и др.

В соответствии с абзацем 3 пункта 16 Приказа Министерства юстиции Российской Федерации от 4 мая 2007 г. № 88 «Об утверждении Разъяснений о применении Правил подготовки нормативных правовых актов федеральными органами исполнительной власти и их государственной регистрации» в случае, если нормативные правовые акты утверждены совместно федеральными органами исполнительной власти и органами (организациями), акты которых не подлежат государственной регистрации в Министерстве юстиции Российской Федерации, и данные органы указаны первыми, нормативные правовые акты представляются на государственную регистрацию федеральным органом исполнительной власти, следующим за указанными органами (организациями) 6 . Таким образом, соглашения о взаимодействии Центральной избирательной комиссии Российской Федерации с федеральными органами исполнительной власти в процессе организации и проведения выборов должны быть зарегистрированы в 
Министерстве юстиции Российской Федерации данными федеральными органами исполнительной власти или организациями (МВД России, ФСБ России, ФНС, ФМС России, ЦБ Российской Федерации и др.). В случае возникновения сомнений относительно обязательности государственной регистрации, окончательное решение вопроса о необходимости государственной регистрации принимает Министерство юстиции Российской Федерации после проведения юридической экспертизы.

Кроме того, необходимо выделить нетипичные нормативные предписания, издаваемые ЦИК России. К группе нетипичных нормативных предписаний относятся нормативно-технические акты. Например, нормативные акты Центральной избирательной комиссии Российской Федерации о нормативах технологического оборудования избирательных комиссий (кабины для голосования, ящики для голосования), о нормативах изготовления и способах защиты избирательных документов, о форме списков избирателей, о форме удостоверений членов избирательных комиссий, об образцах печатей.

Подготовка проектов постановлений, инструкций и иных нормативных актов Центральной избирательной комиссии Российской Федерации осуществляется Аппаратом Центральной избирательной комиссии Российской Федерации ${ }^{7}$. Процедура рассмотрения проектов нормативных актов Центральной избирательной комиссии Российской Федерации описана в статьях 45-46 Регламента Центральной избирательной комиссии Российской Федерации, утвержденного Постановлением Центральной избирательной комиссии Российской Федерации от 28 июня 1995 г. (в ред. от 10 декабря 2008 г.) № 7/46II $^{8}$. При рассмотрении проекта постановления ЦИК России проводит обсуждение. На голосование ставятся поправки, внесенные только членами Комиссии. После голосования поправок проект постановления принимается в целом. При рассмотрении проекта постановления Комиссия вправе: принять постановление, в том числе с поправками, внесенными в ходе его обсуждения; принять постановление за основу с последующей его доработкой и повторным рассмотрением; отложить обсуждение проекта постановления; отклонить проект 
постановления. Закрепленная в Регламенте Центральной избирательной комиссии Российской Федерации правотворческая процедура не содержит положений о проведении экспертизы проектов нормативных правовых актов и иных документов Центральной избирательной комиссии Российской Федерации на коррупциогенность, предусмотренной Постановлением Правительства Российской Федерации от 5 марта 2009 г. № $196^{9}$. Представляется, что данные нормативные предписания должны быть в обязательном порядке закреплены в Регламенте Центральной избирательной комиссии Российской Федерации и нормативных правовых актах избирательных комиссий субъектов Российской Федерации.

Специфика нормотворческой деятельности ЦИК России заключается в том, что согласно пункту 13 статьи 20 Федерального закона «Об основных гарантиях избирательных прав и права на участие в референдуме граждан Российской Федерации», статье 6 Регламента Центральной избирательной комиссии Российской Федерации для вступления в силу нормативных актов ЦИК России их государственная регистрация не требуется. Вместе с тем, большинство нормативных правовых актов ЦИК России и избирательных комиссий субъектов Российской Федерации прямо или косвенно затрагивает права и свободы граждан. В связи с этим процедура государственной регистрации могла бы способствовать не только повышению качества нормативных правовых актов избирательных комиссий, но и содействовать более полной реализации прав и свобод участников избирательного процесса.

Часть 2 статьи 9 Федерального закона «О выборах депутатов Государственной Думы Федерального Собрания Российской Федерации» закрепляет положение, что нормативные акты Центральной избирательной комиссии Российской Федерации вступают в силу после их официального опубликования. Все нормативные акты, а также иные решения ЦИК России публикуются в официальном печатном органе ЦИК России - «Вестнике Центральной избирательной комиссии Российской Федерации» ${ }^{10}$. В статье 47 Регламента Центральной избирательной комиссии Российской Федерации 
содержится предписание о необходимости передачи нормативных актов Центральной избирательной комиссии Российской Федерации в средства массовой информации и размещения указанных актов на Интернет-сайте Комиссии. Нормативные акты и другие решения Центральной избирательной комиссии Российской Федерации, а также решения иных избирательных комиссий, принятые ими в пределах своей компетенции, обязательны для федеральных органов исполнительной власти, органов исполнительной власти субъектов Российской Федерации, других государственных органов, органов местного самоуправления, кандидатов, политических партий и иных общественных объединений, организаций, должностных лиц, избирателей.

Рассматривая нормотворчество избирательных комиссий, необходимо обозначить ряд существующих в данной сфере проблем.

Bo-nервых, федеральное избирательное законодательство не предусматривает права избирательных комиссий субъектов Российской Федерации принимать нормативные правовые акты по вопросам своей компетенции (статья 23 Федерального закона «Об основных гарантиях избирательных прав и права на участие в референдуме граждан Российской Федерации», статья 20 Федерального закона «О выборах Президента Российской Федерации», статья 26 Федерального закона «О выборах депутатов Государственной Думы Федерального Собрания Российской Федерации»). При этом в специальном законодательном акте, регулирующем отношения, возникающие при использовании ГАС «Выборы» (статьи 7, 10 и 18 Федерального закона «О Государственной автоматизированной системе Российской Федерации «Выборы»), предусмотрены правомочия избирательных комиссий субъектов Российской Федерации издавать в пределах своей компетенции нормативные правовые акты по вопросам использования и эксплуатации ГАС «Выборы». В подпункте «и» пункта 10 статьи 23 Федерального закона «Об основных гарантиях избирательных прав и права на участие в референдуме граждан Российской Федерации» упоминается возможность избирательных комиссий субъектов Российской Федерации 
принимать нормативно-технические акты, т.е. устанавливать по поручению ЦИК России нормативы, в соответствии с которыми изготавливаются списки избирателей и другие избирательные документы. Таким образом, нормотворческая деятельность, осуществляемая избирательными комиссиями на региональном уровне, не регулируется в должной мере действующим федеральным законодательством. Между тем, региональный фрагмент нормативного правового регулирования выборов, представленный нормативными правовыми актами избирательных комиссий субъектов Российской Федерации по предмету своего ведения, является необходимым элементом избирательного законодательства субъектов Российской Федерации о выборах. Поэтому нормотворческие полномочия избирательных комиссий субъектов Российской Федерации должны быть законодательно закреплены.

Bo-вторых, в избирательном законодательстве и Регламенте Центральной избирательной комиссии Российской Федерации отсутствуют виды нормативных правовых актов, которые может принимать Центральная избирательная комиссия Российской Федерации. Несмотря на то, что избирательные комиссии не входят в систему органов исполнительной власти, на основе сопоставления наименований нормативных правовых актов органов исполнительной власти и избирательных органов представляется важным уточнить виды принимаемых избирательными комиссиями нормативных правовых актов. В пункте 2 Постановления Правительства Российской Федерации от 13 августа 1997 г. № 1009 (в ред. от 17 марта 2009 г.) «Об утверждении Правил подготовки нормативных правовых актов федеральных органов исполнительной власти и их государственной регистрации» определено, что федеральные органы исполнительной власти издают нормативные правовые акты в виде постановлений, приказов, распоряжений, правил, инструкций и положений ${ }^{11}$. В федеральных законах о выборах и Постановлении ЦИК России от 28 июня 1995 г. (в ред. от 10 декабря 2008 г.) № 7/46- II «O Регламенте Центральной избирательной комиссии Российской Федерации» из числа нормативных правовых актов, 
принимаемых ЦИК России, упоминаются только инструкции. При этом нормативный правовой характер, кроме инструкций Центральной избирательной комиссии, носят положения, регламенты и соглашения.

Думается, что этот пробел правового регулирования требует восполнения. Кроме того, учитывая особенный статус избирательных комиссий в механизме государства, обозначенная проблема актуализирует вопрос принятия Федерального закона «О нормативных правовых актах в Российской Федерации».

Красинский Владислав Вячеславович кандидат юридических наук, эксперт Российского общественного института избирательного права (РОИИП)

Источник публикации: Красинский В.B. О правовой природе актов избирательных комиссий в Российской Федерации // Современное право. 2009. № 11.

${ }^{1}$ См. Нормография: теория и методология нормотворчества / под ред. дра юрид. наук Ю.Г. Арзамасова. М.: Академический проспект; Трикста, 2007. C. 56.

${ }^{2}$ См. Решение Судебной коллегии по гражданским делам Верховного Суда Российской Федерации от 10 ноября 2003 г.

3 См. Протокол заседания Центральной избирательной комиссии Российской Федерации от 3 мая 2007 г. № 6-5-5 «О Методических рекомендациях по реализации избирательных прав военнослужащих и сотрудников правоохранительных органов при проведении выборов Президента Российской Федерации».

${ }^{4}$ См. С3 РФ. 1996. № 49. Ст. 5506.

${ }^{5}$ См. Научно-практический комментарий к Федеральному закону «Об основных гарантиях избирательных прав и права на участие в референдуме граждан Российской Федерации» / под ред. д-ра юрид. наук В.И. Лысенко. М..: Объединенная редакция МВД России, 2007. С. 259.

${ }^{6}$ См. Рос. газ. 2007. 24 мая.

7 См. Пункты 2.4 и 3.9.1 Положения об Аппарате Центральной избирательной комиссии Российской Федерации (утверждено Постановлением Центральной избирательной комиссии Российской Федерации от 31 января 2006 г. (в ред. от 10 декабря 2008 г.) № 169/1100-4). 
${ }^{8}$ См. Вестник ЦИК России. 2003. № 3; 2005. № 12; 2007. № 4; 2008. № 4; 2008. № 9; 2009. № 1.

${ }^{9}$ См. СЗ РФ. 2009. № 10. Ст. 1241.

10 См. Ст. 7 Регламента Центральной избирательной комиссии Российской Федерации.

${ }^{11}$ См. СЗ РФ. 1997. № 33. Ст. 3895; 1997. № 50. Ст. 5689; 1998. № 47. Ст. 5771; 1999. № 8. Ст. 1026; 2002. № 40. Ст. 3929; 2006. № 29. Ст. 3251; 2009. № 2. Ст. 240; 2009. № 12. Ст. 1443. 